Relato de Experiência

\title{
O Skate e suas possibilidades educacionais
}

\author{
Igor Armbrust ${ }^{1}$ \\ Flávio Antônio Ascânio Lauro ${ }^{2}$ \\ ${ }^{1}$ Universidade Camilo Castelo Branco, São Paulo, SP, Brasil e Faculdades Integradas de \\ Santo André- FEFISA, Santo André, SP, Brasil \\ ${ }^{2}$ Centro Universitário Monte Serrat, Santos, SP, Brasil
}

\begin{abstract}
Resumo: Os esportes radicais têm sido objetos de discussões, devido ao interesse de aplicabilidade de seus conteúdos relacionados ao lazer, ao esporte e a educação. Todavia, ainda há certo despreparo profissional para empreender essas atividades, o que dificulta implantar tais práticas nos âmbitos educacionais. Este estudo, de natureza qualitativa, teve como objetivo apresentar uma proposta metodológica para organização de um curso de extensão universitária para graduandos e professores de educação física, com a finalidade de promover reflexões sobre os processos de iniciação à prática do skate atrelados ao esporte educacional. $\mathrm{O}$ estudo constou de pesquisa bibliográfica, apoiada em levantamentos de artigos, teses, dissertações, livros e sites, em que se relacionavam a prática do skate e sua ação educativa. Além disso, houve uma proposição de implementar uma proposta metodológica, no sentido de complementar os elementos da cultura corporal a ser vivenciada em âmbito escolar e efetivamente contribuir no processo de desenvolvimento do ser humano nos aspectos biológico, psicológico, social e cultural.
\end{abstract}

Palavras-chave: Esportes. Educação. Cultura.

\section{The skateboarding and its educational possibility}

\begin{abstract}
The radical sports have been discussions' objects due to the interest of applicability of its contents related to leisure, sport, and education. Nevertheless, there is still some professional unprepared to undertake these activities, which makes difficult to introduce these practices in the educational ambit. This study, which has a qualitative character, had the aim to present a methodological proposal of organizing a college extension course for undergraduate students and teachers of physical education with the goal of promoting reflections about the processes of starting in the skateboarding practice coupled to educational sport. The study was consisted of a bibliographic research supported by a survey of articles, thesis, dissertations, books and, websites related to the skateboarding practice and its educative action. Furthermore, there was the proposal of implementation of a methodology propose in sense of complementing the elements of body culture to be experienced in the educational ambit and contribute effectively in the process of human being development in the biological, psychological, social and, cultural aspects.
\end{abstract}

Key Words: Sports. Education. Culture.

\section{Introdução}

Os esportes radicais, de ação e de aventura, estão sendo cada vez mais abordados em cursos, palestras e oficinas, a mídia está criando uma grande massa consumidora de produtos industrializados que vendem 0 sentido da aventura, por exemplo, por meio de uma determinada marca. Mesmo assim, ainda existem discussões e preconceitos sobre algumas práticas ou praticantes de esportes radicais, por transgredirem alguns princípios e valores tradicionais, como os sujeitos que utilizam os espaços urbanos de maneira dinâmica, empregando manobras sobre um skate nos monumentos da cidade, nos bancos, que antes serviam apenas para sentar, ou os corrimãos de uma escadaria que, agora, além de apoiar as mãos para subir ou descer, os skatistas usamnos para deslizar com 0 skate. Esses preconceitos existiam desde a década de 80 e ainda existem em alguns locais, conforme comenta Brandão (2008) sobre o street skate, o qual se pratica nas ruas.

De que forma melhorar as visões deturpadas sobre tais atividades? Será que esses movimentos ou práticas de esportes radicais seriam mais aceitos se os engajássemos num processo pedagógico que atendesse aos valores educacionais por meio da cultura de movimento? É possível que esse fenômeno possa ser inserido nas vertentes educacionais por meio de um compartilhamento de profissionais de educação física e alunos, um relacionamento fundamental 
às novas vertentes de movimentos. Espera-se favorecer ideias e métodos pedagógicos para implantação de determinadas modalidades, bem como, atender às necessidades encontradas em ministrar aulas deste tipo no âmbito educacional, não apenas nas perspectivas simplistas de um determinado jogo, movimento ou modalidade, mas também, num olhar mais aprofundado sobre as dimensões a serem tomadas para transformação social dos indivíduos inseridos nesse contexto.

Após realizarmos diversas buscas às bases de dados científicos, revistas e artigos referentes às propostas de atividades de aventura atrelada à educação, verificou-se a ausência de métodos de ensino em diversas modalidades da vertente aventura, entre elas, o skate que, atualmente, é um dos esportes mais praticados no Brasil, com aproximadamente 2,7 milhões de adeptos ${ }^{1}$. O número de praticantes cresce a cada dia num esporte que agrega valores históricos, rebeldias e contravenções e que chega ao ápice, até sendo uma profissão para aqueles dedicados competidores que um dia começaram com seus tombos e foram em frente, deslizando e equilibrando-se em eixos, shapes e rodinhas.

Tendo em vista a educação física que se renova, recria e aprimora seus conceitos, conteúdos e didáticas, sugerem-se algumas reflexões sobre propostas contemporâneas e as práticas que vemos constantemente nas ruas, por que não levá-las para a escola, por que não perguntar e conversar com as crianças? Talvez, muitas queiram novas modalidades dentro do âmbito escolar. Às vezes, as crianças já praticam tais atividades nos momentos livres e recreativos, porém se não olharmos para o ser humano em plena formação, talvez algumas desistam no meio do caminho, por não se desenvolverem, nem melhorarem em tais práticas.

Este estudo visa apresentar uma proposta metodológica utilizada no curso de extensão universitária para graduandos e professores de educação física, ministrado pelo professor Igor Armbrust na Universidade Camilo Castelo Branco, com base em levantamentos bibliográficos, para promover reflexões sobre os processos de ensino e aprendizagem do skate, atrelado à vertente dos esportes radicais, de ação e de aventura no âmbito educacional.

\footnotetext{
${ }^{1}$ Folha de São Paulo (folhinha) - 15/06/2003
}

\section{Ascensão dos esportes radicais, de ação e de aventura}

Este fenômeno esportivo, cada vez mais, sofre influência da mídia (UVINHA, 2004), que, de certo ponto, é boa, mas, que precisa de uma compreensão mais difundida e elaborada para referenciar o fenômeno esportivo, o qual, muitas vezes, é apenas oferecido como produto de consumo. Isto ocasiona uma distorção do objeto e propicia alguns pré-conceitos, ao invés de uma ação transformadora (BRANDÃO, 2007).

De acordo com Costa e Tubino (1999), a vertente da aventura existe pelo enfrentamento do risco e surge com o instinto natural de que os seres humanos tinham de experimentar e explorar, como meio de sobrevivência, quando viviam em florestas, cavernas e geleiras e tinham que atravessar rios e montanhas. Marinho (2005) aponta que, na antiguidade, o risco de vida fazia parte do cotidiano dessas pessoas e atualmente, - ser humano desafia a morte de forma metafórica, fictícia ou imaginária, por meio de riscos calculados para produzir determinado prazer, que dê um sentido, mesmo que provisório, à existência humana, saindo do conforto e segurança da vida.

Mas há um contraponto no que diz respeito às formas de controle, pois Spink (2001 p. 1277), sugere a ideia de risco desejado nas atividades de aventura, referindo-se as "subjetividades dos praticantes em contato com as atividades ou eventos que têm incertezas quanto aos resultados ou consequências, essas incertezas são compreendidas como componentes essenciais e propositais do comportamento humano". No risco, o equilíbrio está na percepção risco-competência (lbid).

A expressão radical pode sugerir entendimentos diferenciados. De acordo com Uvinha (2001), a palavra pode remeter ao extremismo, quando aplicada ao campo da política; raiz, quando se busca a origem em alguma coisa, muito frequente na filosofia. $E$ na área dos esportes, a palavra radical se aproxima, muitas vezes, das sensações de risco. O risco, conforme Le Breton (2006) está associado à exposição e à sobrevivência em situações de confronto com a natureza. Trata-se de abandonar, provisoriamente, o conforto e a segurança, de levar o corpo ao limite de seus recursos, de ir o mais longe possível e de jogar com a imprevisibilidade. 
Uvinha (2001) reforça a ideia de expressão arriscada entre os praticantes de esportes radicais e relata que estes jogam a todo 0 momento com o risco de uma queda, de um afogamento, ou qualquer outra ocorrência que possa custar até a vida. $O$ autor, em outro trabalho, mostra que há certa imprecisão quanto aos termos esportes radicais que se confundem com esportes de aventura, com turismo de aventura, esportes extremos, entre outros. Parece haver uma tentativa de fugir do termo radical buscando uma conotação que expresse 0 sentimento e pensamento do verde, da natureza sob a pena de perder um público não familiarizado ao risco (UVINHA, 2005).

Outro olhar para o fenômeno do risco, conforme explica Spink (2005) são as opções de diferentes sentidos que o risco pode conter. Aqui, entendido como conjunto de práticas que recuperam a aventura como divisão positiva dos riscos associado à sociedade contemporânea. Pode haver uma conexão entre o risco e a aventura, valorizada pela ousadia passível de levar a descobertas; risco e aposta, associação da potencialidade de ganhos e perdas e risco e formação de caráter, expressa no valor educativo da aventura. A autora explica que o risco deve ser entendido como algo que tenha probabilidade de ocorrência de um evento indesejável, como os acidentes. A aventura refere-se à busca de desafios relacionados com situações que não se pode prever, ou que não se pode avaliar antecipadamente. $O$ que aponta para a imprevisibilidade de algo.

Bruhns (2009) mostra que a aventura pode ser compreendida como a modulação contemporânea do desejo por outro lugar, que remete ao fugir, ou as coisas sem preço, sem sentido para outros. A autora faz um contra ponto às ideias de Spink, pois acredita que a aventura não está relacionada à questão de ganhar ou perder, mas se constitui em uma forma de experimentar e isso perpassará toda a existência naquele momento, como se não tivesse outro objetivo senão sua realização.

Ainda é difícil apontar para o entendimento do fenômeno radical, pois apresenta uma gama de variedades e termos que alargam mais as ideias centrais deste tema. Percebe-se que a expressão radical aponta para diferentes caminhos se analisarmos os entendimentos na natureza e na área urbana. Sobre as atividades associada à área urbana, como é o caso do skate, objeto de estudo exposto neste trabalho, percebe-se que 0 risco pode estar associado às medidas e análises de uma determinada manobra, ou do deslocamento em maior velocidade numa descida. Ainda podemos refletir sobre a subjetividade que o risco pode se expressar em diferentes pessoas, pois, quanto mais se domina um determinado movimento, mais ousado pode ser o próximo e isso seria durante o processo de aprendizagem e autonomia das práticas ou jogos que os alunos vão absorvendo nas atividades, seja encontrando os amigos para uma sessão de skate, de maneira livre, ou no encontro de aulas com professor e demais colegas da aula.

Esses esportes, cada vez mais, crescem em adeptos e número de atividades. Eles continuam sendo inventados e reinventados e, com isso, surgem variadas nomenclaturas ou terminologias. Para Pereira e Carceroni (2005) e Freire e Schwartz (2005), o crescimento dessas práticas é tão significativo que muitas pessoas acreditam nelas como possibilidades educacionais e formadoras dos cidadãos. Isto remete aos profissionais e educadores, os quais necessitam se apropriar nessa nova cultura corporal, para contextualizar seus conteúdos à nova realidade da educação física.

Os esportes de aventura ganharam tanta importância, que os Parâmetros Curriculares Nacionais (PCN) apresentam, no eixo transversal "Meio Ambiente", para os alunos de $5^{\underline{a}}$ a $8^{\text {a }}$ séries, a necessidade de se realizar uma educação com atividades corporais praticadas junto à natureza: "surfe, alpinismo, bicicross, jetski, entre outros esportes radicais, montanhismo, caminhada, mergulho, exploração de cavernas e atividades de lazer ecológico" (BRASIL, 1998 p.40). Essas atividades praticadas em meio à natureza ou em áreas urbanas ganham espaço na escola, pois estimulam os alunos a testarem a coragem, aliada ao "[...] prazer de práticas em ambientes diversificados fazendo com que conheçam os próprios limites" (ARAÚJO, 2006, p. 41).

Por outro lado, ainda há um despreparo e poucos profissionais capacitados, habilitados e especializados para atuarem com os esportes radicais, dando ênfase, aqui, aos esportes de prancha (LAURO; DANUCALOV, 2005). As universidades começaram a mostrar interesse pelo fenômeno, que teve início com cursos e palestras sobre skate e surfe, em 1995, e 
disciplinas que apontam as vertentes de esportes radicais, de ação e de aventura (PEREIRA et al. 2008).

Diante disso, algumas pesquisas começaram a ser desenvolvidas no Brasil, para acompanhar o crescimento de literaturas no mundo e alguns congressos e cursos de extensão universitária foram realizados, voltados às atividades de aventura (ARMBRUST; BORTOLETTO JR, 2007). Tudo isso, para alavancar e preparar o futuro profissional que trabalhará neste novo segmento. Esses dados supracitados servem de base para se compreender a ótica dos esportes radicais no contexto atual.

\section{O cenário do skate e sua aproximação com a educação}

Existem diversas contradições em relação ao surgimento do skate. A falta de registros precisos e sistematizados impossibilita a atribuição de sua gênese a uma pessoa ou local. Nos Estados Unidos da América, de acordo com Brooke (1999), o skate estaria associado às antigas caixas de laranjas fixadas a uma madeira com rodas, nas décadas de 1920 e 1940, servindo como meio de locomoção entre os jovens estadunidenses. A partir da década de 1950, houve uma aproximação da prática do skate com o surfe, sendo conhecido, nesta década, como "sidewalk surfing" (surfe de calçada). Durante esse período, aconteciam muitos acidentes, devido aos eixos estreitos e rodinhas que eram constituídas de materiais como ferro, borracha ou argila (HONORATO; GEBARA, 2004).

O skate chegou ao Brasil na década de 1960, com as pessoas que começavam a surfar por aqui, influenciadas pelos anúncios nas revistas americanas Surfer. O skate apareceu como forma de vivência no lazer e ficou conhecido como "surfinho". Foram utilizados eixos e rodinhas de patins pregados numa madeira qualquer, para sua composição, sendo as rodas de borracha ou ferro (BRITTO, 2000). O autor aponta que o grande marco na história do skate ocorreu em 1974, quando o engenheiro químico chamado Frank Nasworthy descobriu o uretano, material mais flexível, que oferecia mais aderência às rodas, o que possibilitou novas manobras e um maior número de pessoas inexperientes começarem a prática desta modalidade. O resultado foi a criação de campeonatos, marcas, fábricas e lojas especializadas.
Atualmente, o skate faz aproximações de aprendizagens e práticas, no campo do lazer, em parques, como é o caso do maior complexo de esportes radicais da América Latina, o Parque Cidade Escola "Cittá Di Maróstica", localizado em São Bernardo do Campo (SP), inaugurado em 2007 (PEREIRA; MENEZES, 2008). As aproximações com a educação começaram com as realizações de palestras sobre o contexto histórico do skate no Brasil e no mundo, em 1990, na cidade de São Paulo, ministradas pelo professor Flávio Antônio Ascânio Lauro. Já, em 1997, aconteceu o workshop "Prática e ensino do skate" e, em 2000, foi realizado o I Encontro Acadêmico de Esportes de Aventura (LAURO; DANUCALOV, 2005, p. 114). Além disso, surgiram disciplinas de cursos universitários e de extensão em 2000, pós-graduação em 2002 e outras atividades relacionadas aos esportes radicais, de aventura e de ação (lbid; ARMBRUST; BORTOLETTO JR, 2007).

Diante desses apontamentos filosóficos e históricos sobre o skate no mundo e no Brasil, sua associação com diversas áreas do conhecimento, do surgimento deste esporte até às aproximações com a educação, mostrou-se necessário explanar os fatos e conceitos, para que os participantes do curso de extensão universitária refletissem sobre todo o processo de solidificação desta prática e se apropriassem de elementos constituintes da história. Destarte, os conhecimentos factuais e conceituais, foram fundamentais para aprofundar os campos de estudo do desenvolvimento humano, paralelamente às possíveis estratégias e compreensões do educador para o educando.

\section{Desenvolvimento integral}

Nas aulas de educação física escolar, o professor pode utilizar diversas ferramentas pedagógicas e estratégias de intervenção, por meio de experimentações motrizes que convergem a processos de desenvolvimento motor que se revela, basicamente, por alterações no comportamento motor, durante todo o ciclo da vida, em reação aos desafios enfrentados diariamente, em um mundo em constante mutação. Essas mudanças são provocadas por fatores próprios do indivíduo - biológicos; do ambiente - experiência e da tarefa em si físicos/mecânicos (GALLAHUE; OZMUN, 2001). 
Nesta concepção, o professor que desenvolverá aulas com skate precisa planejar seus objetivos pontuais em relação às atividades e movimentos, sendo estes os grandes diferenciais de aprendizagem numa aula de educação física. Para retratar as atividades e os movimentos correspondentes, Gallahue e Ozmun (2001) sugestionam o agrupamento destes em três categorias: movimentos estabilizadores, movimentos locomotores e movimentos manipulativos, que, por sua vez, podem se combinar.

Para elucidar melhor, um bom exemplo seria a atividade de se deslocar com o skate para um determinado ponto, pois envolve a locomoção de um lugar a outro, manipulação com os pés sobre o skate e estabilidade para se manter equilibrado durante o percurso. Os autores ainda apontam para a necessidade de estabelecer uma sequência adequada para 0 progresso das habilidades motoras ao longo da vida e que coincidam com as fases e estágios de desenvolvimento motor. Por outro lado, sabe-se que o indivíduo não pode ser observado e estimulado apenas para uma direção, citando o desenvolvimento motor.

A educação e o desenvolvimento precisa ser de maneira integrada, como apresentam os estudos de Le Boulch (1988), que corresponde à psicomotricidade, sendo esta a responsável pela formação de base indispensável a toda criança. A psicomotricidade responde a uma dupla finalidade: assegurar 0 desenvolvimento funcional, tendo em conta as possibilidades da criança, e ajudar sua afetividade a se expandir e a equilibrar-se, por meio do intercâmbio com o ambiente humano.

Outra definição importante para a compreensão e complementação do sentido da ciência denominada psicomotricidade está apoiada na "[...] realização de um pensamento através de um ato motor coeso, econômico e harmonioso, exigindo para isso uma afetividade equilibrada." (VELASCO, 1994, p. 16).

Dessa forma, vale reforçar que o compromisso com o educando está nos estímulos prazerosos de se movimentar, agir e sentir. É neste processo educativo que relacionamos a proposta do skate e, por meio do jogo corporal, entendido como mecanismo facilitador do conhecimento, o aluno pode aprender de maneira progressiva os processos de domínio corporal atrelado ao skate. Pode-se pensar em uma criança indo a um supermercado ou qualquer outra loja de produtos esportivos e visualizando um skate na prateleira, isso pode despertar um interesse pelo material ou não, mas se despertar, neste momento, o prazer da criança está no querer o skate. Mesmo que ela adquira o skate, mas nunca foi estimulada a brincar com o objeto, pode implicar numa ação de conflito, pois não aprendeu a se locomover sobre um skate e ainda mais, se não tiver a estrutura adequada, não atingirá o poder da realização, por mais vontade ou conhecimento que tenha e isso poderá ocasionar um desinteresse pelo objeto. Assim, oferecer condições para a criança se reconhecer e relacionar com os objetos e as pessoas que convivem, auxiliará as crianças integrar-se ao mundo (VYGOTSKY, 1998; VELASCO, 1994).

As ideias perspectivadas nesse estudo, assim como os pensamentos de Le Boulch (2008), são de conciliar o respeito à autonomia pessoal e o rigor do aprendizado, tendo em vista uma metodologia que ofereça ao aluno a possibilidade de ser responsável, ele mesmo, por seu aprendizado. Adicionalmente, os educadores precisam atentar às diferenças estruturais e cognitivas das crianças.

Merleau-Ponty (1994) corrobora esse pensamento, quando aborda a terminologia do corpo próprio, que tem o caráter expressivo do movimento quanto elemento principal. Assim, conforme a relação com 0 meio ambiente privilegiado e o corpo estimulado, o indivíduo poderá expressar suas emoções ou será instrumento eficaz de adaptação a determinado movimento. Esse é o ponto fundamental atribuído à educação pelo movimento, dada a motricidade global. Trata-se de transpor o limiar entre o ajustamento global e a programação mental (LE BOULCH, 2008). O desenvolvimento de toda prática, bem como no skate, se sustenta, portanto, na autonomia de um referencial postural que se desencadeia numa perfeita sincronia entre o suporte postural e as ações segmentárias para desenvolver o movimento natural e harmônico.

O meio eficaz e educativo desta proposta apresentada, em correlação com os pensamentos de Le Boulch (2008) e Freire (1987), não é impor um modelo exterior de maneira autoritária, mas avaliar a lógica interna das atividades e sua relação, ou referência à 
própria imagem que se faz do corpo. Essa associação visa respeitar as idades e permite 0 experimentar por meio de automatismos posturais próprios, em que o professor media as situações de ajustes e introduz a dimensão da personalidade do aluno e de suas próprias possibilidades, mas também, o desejo de aprender cada vez mais.

O desenvolvimento das atitudes positivas diante do conhecimento não pode ser ignorado pelo professor. É interessante que o profissional de educação física propicie estratégias e momentos adequados, nas suas aulas de skate, onde os alunos possam saber o que aprenderam e, também, que eles possam expressar o que sabem e não apenas repetir o que lhes pedem ou tentam ensinar de um modo fragmentado. A educação para a autonomia, conforme estamos propondo, condiz com certas condutas, como o exemplo de guardar os skates após as aulas e preservá-los, oportunizar escolhas, privilegiar as atividades em grupos, construir as regras e mudá-las, permitir que os alunos tracem estratégias e, principalmente, que as testem para, assim, refletirem se foi boa ou não.

Cabe ao educador não acelerar o processo de respostas. "Não fazer pela criança o que esta pode fazer sozinha" (SANTANA; REIS, 2006, p. 148). O papel do professor de educação física, que está em busca da construção de conhecimentos contemporâneos, como nesta proposta de skate e suas possibilidades educacionais, é de prover segurança e estímulo ou de regulador, para facilitar a experiência de conflito com o problema surgido num determinado jogo, atividade ou proposta. Essa conduta não deve gerar uma facilitação, a ponto de desinteresse por perda de imprevisibilidade ou algo do gênero, em uma determinada ação ao jogo que foi proposto. Oferecer ajuda ao aluno no plano operativo não consiste em ensinar o aluno a solução certa ou a que o professor deseje, mas orientar seus esforços e sua atenção perceptiva ao movimento, tarefa ou algum acontecimento do jogo (GALLAHUE; OZMUN, 2001; LE BOULCH, 2008).

As reações iniciais de crianças pequenas são relações motoras e todos os dados conceituais e perceptivos futuros estão baseados, em parte, nessas reações iniciais. Quanto mais experiências de aprendizado motor e perceptivo tiverem as crianças, sob o controle, manuseio e manobras sobre o skate, maior a oportunidade de que elas façam essa combinação e desenvolvam certa plasticidade de reação às diversas situações psicomotoras. Por outro lado, a ausência de experiências motoras variadas nas aulas de skate, que remontem adaptações sem sentido ou conexão, além da repetição imposta, pode reprimir o desenvolvimento motor. Logo, cabe ao educador criar diversas atividades fundamentadas numa sequência lógica e que respeitem o nível de desenvolvimento de cada indivíduo.

\section{A dimensão lúdica dos jogos associados ao skate}

Os recursos didáticos apresentados neste estudo foram construídos com base nos pressupostos dos jogos, pois estes são atividades ricas em situações imprevistas, às quais o indivíduo tem de responder prontamente, assumindo algumas responsabilidades em conjunto com o risco (ROSSETO JR et al., 2005).

\begin{abstract}
Os jogos e os esportes proporcionam a experiência de situações de convivência e conflito, transferíveis para o cotidiano familiar, escolar e do mundo do trabalho, em dinâmicas com diferentes graus de competitividade e cooperação (ROSSETO JR et al., 2005, p. 14).
\end{abstract}

Huizinga (1996) e Vygotsky (1998) apontam que o jogo é uma atividade representativa e interpretativa e que acontece naquele momento, não sendo apenas imaginária, afirmando até um misto de vivências concretas com o mundo fantasioso, imaginário. Dessa forma, os autores concordam que o jogo transforma as pessoas que o praticam, o que faz surgir pequenas sociedades em torno do jogo, conflitando com regras, aceitação do grupo e expressões de valores e comportamentos, potencializando assim, o desenvolvimento da socialização.

Um costume ou uma prática de um determinado
grupo não devem ser vistos como certos ou
errados, melhores ou piores do que outros do
nosso próprio grupo. Ambos têm significados
próprios que os justificam no âmbito do grupo no
qual ocorrem. Portanto, a diferença não deve
ser pensada como inferioridade. O que
caracteriza a espécie humana é justamente sua
capacidade de se expressar diferenciadamente.
(DAOLIO, 2005, p. 100).

Destarte, as contribuições de jogos associados ao skate como possibilidades educativas, serviram de base para subsidiar os educadores que estavam no curso de extensão universitária. As estratégias e critérios para estimular jogos foram referenciadas e adaptadas de Freire (2003) e Rosseto Jr et al. (2005).

- Possibilitar "participação de todos", mesmo os que não estão executando 0 movimento propriamente dito. Por exemplo, em um jogo, no 
skate, denominado de "mata-barata", que consiste em deslocar-se sobre o skate, de um ponto a outro sem colocar os pés no chão, poderia adaptar algumas ações, em que alguns alunos se deslocassem como auxiliadores daqueles que têm dificuldades. A participação deve ser efetiva ao jogo proposto, ou seja, todos precisam ser inseridos na ação do jogo.

- O jogo precisa atender ao "sucesso dos participantes". Deve-se planejar os ajustes diante das dificuldades de cada indivíduo, o jogo não pode ser muito fácil nem muito difícil, mas desafiador e que motive a participação. Por exemplo: um jogo de skate que consiste em realizar uma travessia de um lado da quadra para o outro, pode ser fácil para alguns e difícil para outros. Ao se refletir nos critérios de tomada de decisão, poderia ser pedido aquele que se deslocou primeiro de uma forma, que, na volta, se desloque de modo diferente, ou, então, adotar-se o jogo do "invente outra", que consiste em atravessar de um lugar para outro após um comando, que pode partir inclusive dos próprios alunos. Quando estiverem atravessando, aquele que visualizar o outro se deslocando da mesma forma gritará "invente outra" para este, o qual terá que mudar a forma que estava se deslocando.

- Além desses critérios, o professor deve diminuir suas interferências no jogo para propiciar "gerenciamento dos jogadores". A ideia é que os alunos consigam, com o tempo, resolver os problemas e conflitos gerados no grupo.

- Ainda os jogos devem "favorecer adaptações e novas aprendizagens". Cabe ao professor criar condições e espaços para as experimentações e repetições de habilidades motoras envolvidas no jogo.

- Por fim, o jogo deve manter certa "imprevisibilidade", tanto nas organizações de grupos, quanto nas dinâmicas de atividades.

De acordo com Rosseto Jr et al. (2005), as atividades ou o próprio jogo não precisa ser traçado com exatidão, menos ainda seus resultados. Isso vai ao encontro do pensamento dos esportes radicais e seus elementos caracterizadores, como a exploração, a intuição, a experimentação, entre outros.

Os estímulos às novas atividades, como o skate podem objetivar alguns apontamentos e perspectivas educacionais para o estreitamento dos conteúdos atrelados à cultura corporal de movimento. Daolio (2005) cita as ginásticas, os jogos, as atividades rítmicas expressivas, as lutas e o esporte cuja aproximação do skate neste cenário contemporâneo, pode efetivamente relacionar as contribuições de um esporte educacional que se estrutura com alguns princípios e posicionamentos que o professor precisa assumir.
- "Ensinar esporte a todos". Qualquer pessoa pode aprender um determinado esporte, seja o futebol ou o skate. O professor deve dar a devida atenção aos alunos, para que se desenvolvam num ambiente adequado, atentando para os progressos de aprendizagem de cada indivíduo, respeitando o ritmo e as habilidades de cada um.

- "Ensinar bem o esporte a todos". Planejar uma sequência pedagógica que propicie 0 aprendizado de maneira efetiva, observando as dificuldades de cada aluno e associando possíveis interferências e ajudas, estimulando as melhores técnicas e cuidados, para que os alunos possam expressar as habilidades do esporte aprendido com as devidas qualidades.

- "Ensinar a gostar de esporte". Além das habilidades motoras que podem ser transferidas a outras modalidades da cultura corporal, o aluno pode aprender a conviver em grupos, a construir regras, a discutir e, até mesmo, discordar dessas regras e mudá-las. Dessa forma, o processo pode estimular os desenvolvimentos moral e social da criança.

- "Ensinar mais que esporte". As práticas e os aprendizados serão efetivos, se passarem pelo prazer de fazer certa atividade. O querer fazer é a chave do sucesso para os alunos continuarem a realizar suas atividades motoras em outros lugares e momentos de suas vidas.

Essa aproximação do skate como ferramenta educacional remonta às ações de aulas lúdicas, que valorizem o aluno pelas boas ações, que respeitem e dêem atenção a todos, que ensinem por meio de brincadeiras. Dessa forma, realmente, se faz uma transformação social e não por práticas exaustivas e repetitivas para objetivar um determinado gesto técnico impregnado de condutas lapidadas e moldadas.

\section{Considerações}

Diante desses apontamentos teóricos e algumas reflexões de atividades explicativas que aproximaram e relacionaram os conteúdos de conceitos, procedimentos e atitudes sobre 0 desenvolvimento do indivíduo por meio de práticas motoras, retratar o universo do skate enquanto atividade alternativa e estimulante no ambiente educacional não é tarefa fácil. Os trabalhos acadêmicos que relacionam as atividades de aventura, no caso o skate como proposta educacional, ainda são pouco divulgados, sem demérito às excelentes pesquisas encontradas. Também se percebem poucos cursos de graduação em educação física e pós-graduações que discutem os assuntos dos esportes radicais com profundidade e suas possíveis interfaces com meios competentes para a licenciatura ou o bacharelado. Diante disso, 
esse estudo permite apoiar algumas ideias de que existe um despreparo profissional e que poucos cursos de capacitação para esse segmento são oferecidos. Estima-se um crescimento e atenção para as novas disciplinas na grade curricular de educação física de instituições formadoras, que propiciem reflexões e atividades práticas de esportes radicais, de aventura e de ação para atender essa defasagem.

Essa proposta se prontificou a servir de reflexão para possíveis apontamentos educacionais que aprofundem a dinâmica lúdica do jogo como elemento facilitador para o esporte educacional aqui defendido, sem a pretensão de esgotar o assunto em discussão na área acadêmica. Presta-se, ainda, como um ato de colaboração aos colegas de profissão que ministram aulas na educação física escolar. Também serve de alerta às instituições universitárias, que acreditam no eixo norteador dos currículos nacionais, que almejam ampliar o leque de diversidade de conteúdos e de colaborar e complementar com mais elementos da cultura corporal para efetivar o processo de desenvolvimento do ser humano nos aspectos biológico, psicológico, social e cultural, sem fazer nenhuma dicotomia do ser humano.

Por fim, este estudo procurou corroborar os pensamentos psicomotores como agentes construtores do saber, do fazer, do ser e do conviver, por meio das relações afetivas entre professores e alunos, para que se permita a efetivação do movimento criativo e participativo de novas possibilidades educacionais.

\section{Referências}

ARMBRUST, I.; BORTOLETTO JR, A. R. As atividades de aventura na universidade. In: CONGRESSO BRASILEIRO DE ATIVIDADES DE AVENTURA, 2., 2007, Governador Valadares Mg. ANAIS... Minas Gerais, 2007.

BRANDÃO, M. M. Natureza e aventura: A mídia e seus mitos. In: II CONGRESSO BRASILEIRO DE ATIVIDADES DE AVENTURA, 2007, Governador Valadares Mg. ANAIS... Minas Gerais, 2007

BRANDÃO, L. Entre a marginalização e a esportivização: elementos para uma história da juventude skatista no Brasil. Revista de história do esporte, v. 1, n. 2, p. 1-24, dez. 2008.

BRASIL. Secretaria de Educação Fundamental. PCN: Educação Física/ Secretaria de Educação Fundamental - Brasília: MEC/ SEF, 1998.
BRITTO, E. A Onda Dura: 3 Décadas de Skate no Brasil. São Paulo, editora Parada Inglesa, 2000. 112 p.

BROOKE, M. The concrete wave: the history of skateboarding. EUA: Warwick House Publishing, 1999.

BRUHNS, H. T. A busca pela natureza: turismo e aventura. Barueri, São Paulo: Manole, 2009. $191 \mathrm{p}$.

COSTA, V. L. M.; TUBINO, M. J. G. A Aventura e o risco na prática de esportes vinculados a natureza. Motus Corporis, Rio de Janeiro, v 6, n. 2, p. 96 -112, nov. 1999.

DAOLIO, J. Da cultura do corpo. 9. ed. Campinas, São Paulo: Papirus, 2005.104 p.

FREIRE, J. B. Pedagogia do futebol. Campinas, São Paulo: Autores Associados, 2003. 98 p.

FREIRE, M.; SCHWARTZ, G. M. A caminhada na natureza nas aulas de educação física: consolidando atitudes pró-ativas. FONTOURA, P. (Org.). Coleção pesquisa em educação física. Jundiaí: Fontoura, v. 4, n. 4, p. 7-10, jun. 2005.

FREIRE, P. Pedagogia do oprimido. 17. ed. Rio de Janeiro: Paz e Terra, 1987. 185p.

GALLAHUE, D. L.; OZMUN, J. C. Compreendendo o desenvolvimento motor: bebês, crianças, adolescentes e adultos. Tradução Maria Aparecida da Silva Pereira Araújo. São Paulo: Phorte, 2001. 641 p.

HONORATO, T.; GEBARA, A. Esportes radicais e tecnologização. In: III Congresso Científico Latino-Americano de Educação Física UNIMEP, 2004, Piracicaba-SP. III Congresso UNIMEP. Piracicaba,SP : UNIMEP, 2004. v. 01.

HUIZINGA, J. Homo ludens. Tradução de João Paulo Monteiro. 4. ed. São Paulo: Perspectiva, 1996. 240 p.

LAURO, F. A. A.; DANULACOV, M. A. D. O elemento aventura no meio universitário - $A$ formação acadêmica pelos esportes com prancha. In: UVINHA, RICARDO. RICCI. (Org.) Turismo de Aventura: Reflexões e Tendências. São Paulo: Aleph, 2005. p.103-136.

LE BOULCH, J. M. O corpo na escola no século XXI: práticas corporais. Tradução Cristiane Hirata. São Paulo: Phorte, 2008. 383 p.

LE BOULCH, J. M. Educação psicomotora: psicocinética na idade escolar. Tradução de Jeni Wolff. 2. ed. Porto Alegre: Artes Médicas, 1988. $356 \mathrm{p}$. 
LE BRETON, D. Risco e lazer na natureza. In: MARINHO, A.; BRUHNS, H. T. (Org.). Viagens, lazer e esporte: o espaço da natureza. Barueri, São Paulo: Manole, 2006. p. 94-117.

MARINHO, A. Atividades de Aventura em ambientes artificiais, In: RICARDO RICCI UVINHA (Org.). Turismo de Aventura.

Reflexões e Tendências. São Paulo: Aleph, 2005. p. 247-268.

MERLEAU-PONTY, M. Fenomenologia da percepção. São Paulo: Martins Fontes, 1994. $662 \mathrm{p}$.

PEREIRA, D. W.; CARCERONI, D. S. Atividade de Aventura: Um programa para Educação Física Escolar. CONGRESSO NACIONAL DE EDUCAÇÃO FÍSICA DA UNISA, 2005, Anais

Educação Física e Conhecimento: da heteronomia "útil" à autonomia "inútil", São Paulo, 2005.

PEREIRA, D. W.; CARCERONI, D. S.; MENEZ, E. O skate em São Bernardo do Campo: In CONGRESSO BRASILEIRO DE ATIVIDADES

DE AVENTURA, 3.; CONQUISTANDO NOVAS VIAS, 2008, Santa Teresa/ES. ANAIS... Espírito Santo, 2008.

PEREIRA, D. W.; CARCERONI, D. S.; MENEZ, E.; ARMBRUST, I.; RICARDO, D. P. Esportes radicais, de aventura e ação: conceitos, classificações e características. Revista Corpoconsciência. São Paulo, v.12, n.1, p. 3556, jan/jun. 2008.

ROSSETO JÚNIOR. et al. Jogos educativos: estrutura e organização da prática. São Paulo. Phorte, 2005. 96 p.

SANTANA, W. C.; REIS, H. H. B. A pedagogia do esporte e o desafio de educar para a autonomia. IN: MOREIRA, E. C. (org.) Educação física escolar: propostas e desafios II. Jundiaí: Fontoura, 2006. 183 p.

SPINK, M. J. P. Trópicos do discurso sobre risco: risco-aventura como metáfora na modernidade tardia. Caderno Saúde Pública, Rio de Janeiro vol.17, n.6, nov/dez. 2001. Disponível em <http://www.scielo.br/scielo.br > acesso em: 16 mar. 2004.

SPINK, M. J. P.; ARAGAKI, S. S.; ALVES, M. P. Da exacerbação dos sentidos no encontro com a natureza: Contrastando esportes radicais e turismo de aventura. Psicologia: Reflexão e crítica, São Paulo. v. 8, n.1, p. 26-38. 2005. Disponível em $<$ http://www.scielo.br/pdf/prc/v18n1/24814.pdf > acesso em: abr. 2007.
UVINHA, R. R. Esportes radicais e turismo: Análise conceitual. In: TRIGO, L. G. G.; PANOSSO NETTO, A.; CARVALHO, M. A.; PIRES, $P$. S. Análises regionais e globais do turismo brasileiro. São Paulo: Roca, 2005. p. 437-447.

UVINHA, R. R. Esportes radicais nas aulas de Educação Física no ensino fundamental. In: MOREIRA, E. C. (org.) Educação Física Escolar - desafios e propostas. Jundiaí: Fontoura, 2004. p. 99-111.

UVINHA, R. R. Juventude, lazer e esportes radicais. Barueri, São Paulo: Manole, 2001. p. 102.

VELASCO, C. G. Habilitações e reabilitações psicomotoras na água. São Paulo: Harbra, 1994. 90 p.

VYGOTSKY, Lev. A formação da mente: o desenvolvimento dos processos psicológicos superiores. Tradução José Cipolla Neto, Luís Silveira Menna Barreto, Solange Castro Afeche. 6. ed. São Paulo: Martins, 1998. 190 p.

\author{
Endereço: \\ Igor Armbrust \\ Rua Iguaré, 72 Apto 93 BI 01 - Tatuapé \\ São Paulo SP Brasil \\ 03077-010 \\ Telefone: (11) 2841.3606 \\ e-mail: rumoaventuras@gmail.com
}

Recebido em: 10 de outubro de 2009.

Aceito em: 27 de abril de 2010.

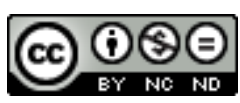

Motriz. Revista de Educação Física. UNESP, Rio Claro, SP, Brasil - eISSN: 1980-6574 - está licenciada sob Licenca Creative Commons 